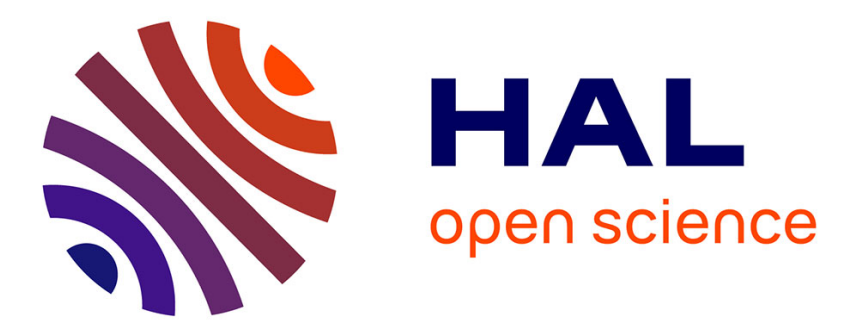

\title{
Mechanism Insight into the Constitutional Phase Change Selection of Dynameric Framework Libraries
}

\author{
Yan Zhang, Mihail Barboiu
}

\section{To cite this version:}

Yan Zhang, Mihail Barboiu. Mechanism Insight into the Constitutional Phase Change Selection of Dynameric Framework Libraries. ACS Omega, 2018, 3 (1), pp.329 - 333. 10.1021/acsomega.7b01645 . hal-01757235

\author{
HAL Id: hal-01757235 \\ https://hal.umontpellier.fr/hal-01757235
}

Submitted on 25 May 2021

HAL is a multi-disciplinary open access archive for the deposit and dissemination of scientific research documents, whether they are published or not. The documents may come from teaching and research institutions in France or abroad, or from public or private research centers.
L'archive ouverte pluridisciplinaire HAL, est destinée au dépôt et à la diffusion de documents scientifiques de niveau recherche, publiés ou non, émanant des établissements d'enseignement et de recherche français ou étrangers, des laboratoires publics ou privés.

\section{(c)(1)}

Distributed under a Creative Commons Attribution| 4.0 International License 


\title{
Mechanism Insight into the Constitutional Phase Change Selection of Dynameric Framework Libraries
}

\author{
Yan Zhang ${ }^{\dagger}$ and Mihail Barboiu*(i) \\ Adaptive Supramolecular Nanosystems Group, Institut Européen des Membranes, Université de Montpellier, ENSCM, CNRS, Place \\ Eugène Bataillon, CC047, F-34095 Montpellier, France
}

\section{Supporting Information}

ABSTRACT: We show that the use of reversibly connected trialdehyde cores and diamine hydrophilic/hydrophobic connectors may generate libraries of dynameric frameworks of variable composition. The dynamic reversible imine- and trans-imination reactions induce the progressive segregation of libraries consisting of homo- and heterodynameric frameworks through the constitutional selection and successive precipitation of low-soluble hydrophobic films and hydrophilic/hydrophobic core-shell particles. This "precipitation-driven segregation" results in the formation of membrane with unique asymmetric morpholgy. Systematic compositional changes of dynamers, segregating solvents, and casting surfaces were correlated with the emerged membrane structure, and NMR/transmission electron microscopy-energy-dispersive X-ray characterizations mostly supported their hypothesis.
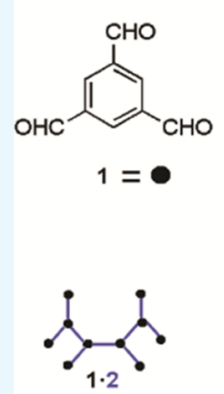

Homodynamer

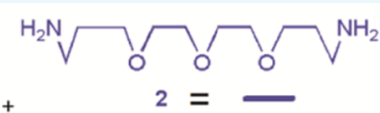

$+$
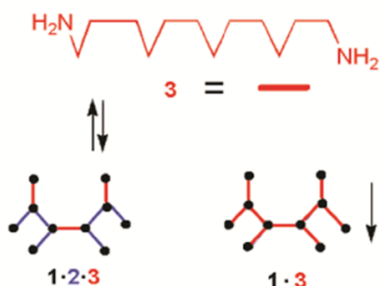

Heterodynamer

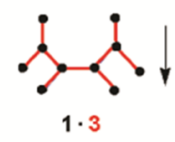

Homodynamer

\section{INTRODUCTION}

Chemical synthesis by design produces a vast number of complex materials. Various approaches have been proposed to design self-assembled materials, and supramolecular chemistry has played an important role in this exploration. ${ }^{1,2}$ Constitutional synthesis by selection provides an evolutional approach for the generation of adaptive materials. Most scenarios are related to the self- and target driven- selection of the optimal structures from dynamic libraries. By combining reversible covalent bonds with supramolecular interactions, constitutional dynamic chemistry, covering the systems emerging by selection, enables the synthesis of materials with unexpected topologies and functions. ${ }^{3}$ However, only very few materials resulted from the constitutional selection of dynamic phases have been reported to date. Moreover, the general mechanistic criteria explaining the emergence of such hierarchical dynamic materials are lacking.

As a result of reversibility, the mixtures of the library can interconvert to give a complex distribution of components under thermodynamic control. Addition of stimuli that selectively interact with one component of the library or irreversible phase change processes will result in one component at the expense of the others in the mixture. This has been evaluated at a molecular level, while libraries of polymeric networks have not been studied yet. Our studies presented here provide the first insight into the constitutional selection of dynameric frameworks at a macromolecular level.

Dynamic polymers-dynamers have emerged as a new class of materials with adaptive behaviors. ${ }^{4-10}$ Their responsive features direct the amplification of components arising from the dynamic libraries of monomers in response to internal structural pressure or applied external stimuli to give rise to interconnected domains of specific compositions and properties.

We have recently discovered that hydrophobic/hydrophilic (HP/HY) agonist monomers can be used for the preparation of asymmetric membranes for directional water transport. ${ }^{11} 1,3,5-$ Benzenetrialdehyde 1, core-center, HY 4,7,10-trioxa-1,13tridecane-diamine 2, and HP 1,12-diamino-dodecane 3 have been connected via reversible amino-carbonyl/imine chemistry, resulting in the formation of various dynameric frameworks in solution (Scheme 1). This work built on the preliminary observation showed that the incorporation of both HP and HY is crucial for the phase-segregation process under the pressure of their internal structural affinity, while the inclusion of only one HP or HY partly afforded a membrane of similar sides. ${ }^{11} \mathrm{~A}$ solvent plays an important role in the extent of phase segregation: acetonitrile $\left(\mathrm{CH}_{3} \mathrm{CN}\right)$ proved to be the most efficient segregating solvent among others $\left(\mathrm{CHCl}_{3}, \mathrm{THF}\right.$, etc.), leading to asymmetric membranes. At this point, the overall structural membrane formation pathways and the mechanism were unknown. In this paper, we give in-depth understanding of the dynamic phase-segregation mechanism, leading to the formation of asymmetric membranes.

\section{RESULTS AND DISCUSSION}

Within this context, complete investigations on the role of the component mixture or the nature of the casting surface on

Received: October 26, 2017

Accepted: December 27, 2017

Published: January 11, 2018 
Scheme 1. Reaction between 1,3,5-Benzenetrialdehyde 1, 4,7,10-Trioxa-1,13-tridecanediamine 2 , and 1,12-

Diaminododecane $3(1 / 2 / 3=1: 0.75: 0.75)$, Resulting in the Formation of a Library of an Exchanging Homodynamers $1 \cdot$ 2 and $1 \cdot 3$ and Heterodynamer $1 \cdot 2 \cdot 3$

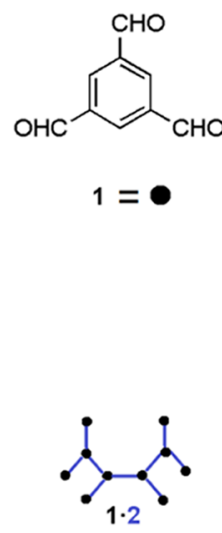

Homodynamer
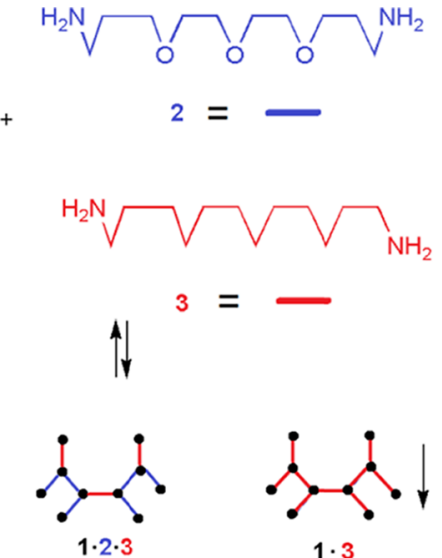

Heterodynamer

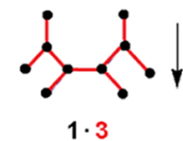

Homodynamer dynamic selection mechanisms have been performed. They are based on sequential emergence of distinct low-soluble homomeric $\mathrm{HP}$ films and heteromeric $\mathrm{HP} / \mathrm{HY}$ microparticles from dynameric libraries, followed by the formation of asymmetric membrane films.

${ }^{1} \mathrm{H}$ NMR spectroscopy has been used to follow the equilibrium occurring in $\mathrm{CD}_{3} \mathrm{CN}$ solution at $60{ }^{\circ} \mathrm{C}$ for the formation of homodynamers $\mathbf{1 . 2}$ and $\mathbf{1 . 3}$ and of heterodynamer $\mathbf{1 \cdot 2 \cdot 3}$ (Figure 1). A white precipitate began to form in the NMR

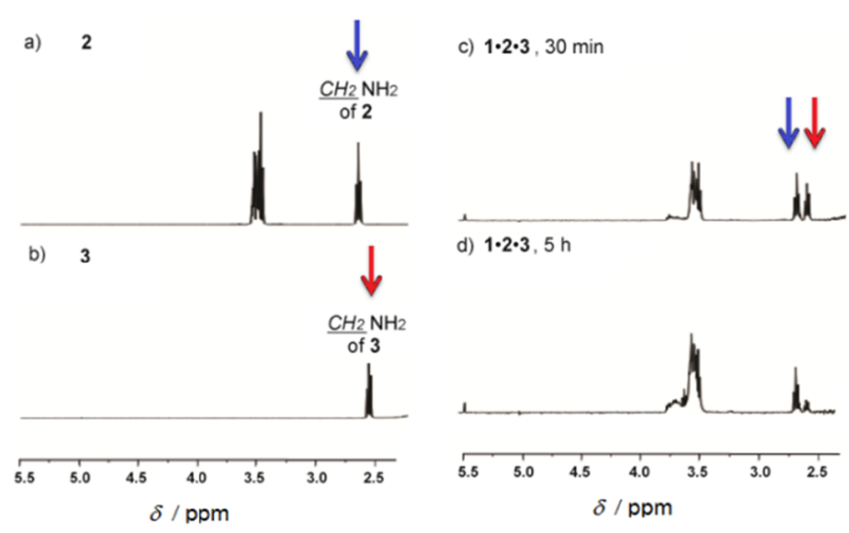

Figure 1. Part of the ${ }^{1} \mathrm{H}$ NMR spectra following the reaction between the starting components: (a) 2 and (b) 3 , resulting in the formation of dynameric libraries of $\mathbf{1 \cdot 2 \cdot 3}$ in $\mathrm{CD}_{3} \mathrm{CN}$ (c) $30 \mathrm{~min}$ and (d) $5 \mathrm{~h}$.

tube after $10 \mathrm{~min}$ at $60{ }^{\circ} \mathrm{C}$. The experiment has been followed by the decrease of peaks at $2.5-2.8 \mathrm{ppm}$, corresponding to the $-\mathrm{CH}_{2} \mathrm{NH}_{2}$ protons and first monitoring the consuming of 2 and 3, while the emerging imine peaks at $8.0-8.5 \mathrm{ppm}$ end up with two simplified peaks from $\mathbf{1 \cdot 2}$ (Figure S4). The fact that the decreasing rate of the HP 3 peak is faster than that of the HY 2 peak suggests that HP homodynamer $1 \cdot 3$ precipitates from the solution prior to HY homodynamer $\mathbf{1 \cdot 2}$ or hybrid heterodynamer $\mathbf{1} \cdot \mathbf{2} \cdot \mathbf{3}$. It means that coupling of the dynamic exchanges of dynamers in the library to an irreversible phase change/precipitation process drives the library out of equilibrium through the progressive formation of distinct $\mathrm{HP}$ and the $\mathrm{HP} / \mathrm{HY}$ phases until the building blocks are consumed. $^{12-14}$

To confirm the hypothesis of precipitation-driven segregation, we conducted experiments in $\mathrm{CH}_{3} \mathrm{CN}$ by casting the solution on HP Teflon, M1, or HY glass M2 surfaces. A similar elemental distribution between $\mathbf{M} 1$ and $\mathbf{M} 2$ in energydispersive X-ray (EDX) spectroscopy was observed on the two sides of membranes (Table 1). Scanning electron

Table 1. Atomic Composition Measured by EDX for Membranes M1-M3 (Ratio 1/2/3 = 1:0.75:0.75) Made from Different Solvents and on Different Template Surfaces

\begin{tabular}{lllllr} 
& & & $\mathrm{C} \%$ & $\mathrm{~N} \%$ & $\mathrm{O} \%$ \\
Teflon & $\mathrm{CH}_{3} \mathrm{CN}$ & top-side & 70.6 & 13.6 & 15.7 \\
M1 & & bottom-side & 78.0 & 13.8 & 8.2 \\
glass & $\mathrm{CH}_{3} \mathrm{CN}$ & top-side & 71.4 & 13.5 & 15.0 \\
M2 & & bottom-side & 76.9 & 17.0 & 6.0 \\
Teflon & $\mathrm{CHCl}_{3}$ & top-side & 79.6 & 11.8 & 8.6 \\
M3 & & bottom-side & 80.4 & 11.2 & 8.4 \\
\hline
\end{tabular}

microscopy (SEM) micrographs showed compacted dense bottom surfaces obtained by casting on glass, whereas porous microparticle patterns are obtained by casting on Teflon (Figure S8).

Dynamic light scattering (DLS) experiments with dynamer 1.2.3 (1:0.75:0.75) in $\mathrm{CH}_{3} \mathrm{CN}$ solution showed particles of a diameter of $300 \mathrm{~nm}$, whereas the particle size for dynamer $\mathbf{1} \cdot \mathbf{2}$ (1:1.5) is around $1 \mu \mathrm{m}$, and only precipitates were detected for dynamer $1.3(1: 1.5)$, suggesting the tendency of forming coreshell microparticles for the HY part and the precipitation-driven membrane formation process. Another test was performed by changing the solvent from $\mathrm{CH}_{3} \mathrm{CN}, \mathrm{M1}$ to $\mathrm{CHCl}_{3}, \mathbf{M} 3$ and using a Teflon template. We observed better solubility of homodynamer $\mathbf{1} \cdot 3$ in $\mathrm{CHCl}_{3}$ that diminishes the segregation effects initiated via its precipitation. As a result, EDX gave a similar elemental distribution between the two sides for all the elements for M3 (Table 1). The SEM images showed completely flat and compact surfaces from both sides (Figure S8). Therefore, the solubility of reversibly generated dynamers is directly related to the phase segregation, providing asymmetric membranes with mainly HP dynamers on the bottom side and HY dynamers on the top side surface.

Transmission electron microscopy (TEM) has been used for a more precise EDX elemental distribution analysis. We detected a gradual decreasing ratio of N/O from 67 to $48 \%$ along the cross section of the membrane M1 (Figure 2), clearly demonstrating the increasing amount of O-containing $\mathrm{HY}$ part (2) from one side to the other side of the film.

After understanding the solubility effects on the dynamic phase segregation, the membranes M4-M7 with different HY. HP 2/3 molar ratios were further prepared from $\mathrm{CH}_{3} \mathrm{CN}$ and casted on Teflon. The EDX results showed that with an increased amount of HP 3, the differences of the elemental distribution of $\mathrm{C} \%$ and $\mathrm{O} \%$ between the two sides were getting larger and larger as expected: more $\mathrm{C} \%(\mathrm{HP})$ and less $\mathrm{O} \%$ (HY) accumulated at the bottom (Table 2). These results have proven again that the lower solubility of homodynamer $\mathbf{1}$. 3 induced its prioritized precipitation at the bottom. The SEM micrographs of M4-M7 showed that the top side of all films was presented as porous structures, whereas the bottom side surfaces are flat and dense, containing a higher amount of HP 3 (Figure 3). 


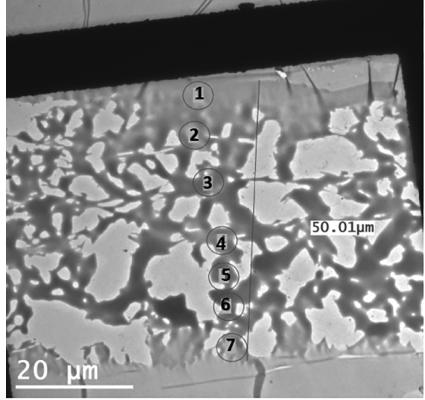

$\begin{array}{cccc}\text { Zone } & \% \mathrm{~N} & \% \mathrm{O} & \begin{array}{c}\text { Ratio } \\ \% \mathrm{~N} / \% \mathrm{O}\end{array} \\ 1 & 40.1 & 59.9 & 0.67 \\ 2 & 36.7 & 60.3 & 0.66 \\ 3 & 37.5 & 62.4 & 0.63 \\ 4 & 37.7 & 62.9 & 0.55 \\ 5 & 36.7 & 63.3 & 0.52 \\ 6 & 29.7 & 70.3 & 0.48 \\ 7 & \text { nd } & \text { nd } & \text { nd }\end{array}$

Figure 2. TEM image of the cross section of M1, and the relative elemental distributions of $\mathrm{N}$ and $\mathrm{O}$ along the cross section of the membrane. We note that only $\mathrm{N}$ and $\mathrm{O}$ elements are considered.

Table 2. Atomic Composition Measured by EDX for Membranes Made with Different Molar Ratios 2/3 on Teflon Supports

\begin{tabular}{clrrr} 
1/2/3 $(\mathrm{mol} / \mathrm{mol})$ & & $\mathrm{C} \%$ & $\mathrm{~N} \%$ & $\mathrm{O} \%$ \\
1:1:0.5 & top-side & 78.7 & 10.3 & 10.9 \\
M4 & bottom-side & 78.7 & 10.2 & 11.0 \\
1:0.9:0.6 & top-side & 80.7 & 9.6 & 9.6 \\
M5 & bottom-side & 83.3 & 9.5 & 7.2 \\
1:0.6:0.9 & top-side & 81.3 & 9.7 & 8.8 \\
M6 & bottom-side & 85.9 & 10.0 & 3.9 \\
1:0.5:1 & top-side & 78.1 & 11.0 & 10.8 \\
M7 & bottom-side & 86.9 & 9.8 & 3.2 \\
\hline
\end{tabular}

Highly regular microparticles could be observed at the bottom side, especially when diamines 2 and 3 were both used. The EDX data indicated that these microparticles contain both
$\mathrm{HY} / \mathrm{HP}$. Increasing the amount of HP 3, the diameter of the microparticles decreases such that the bottom side of the membrane turned to be more densely packed, resulting in the formation of smaller pores.

These results have proven that dynamic reversible exchanges occurred in solution via reversible imine formation and transimination reactions, with the possibility of forming all potential cross-linked frameworks $(\mathbf{1} \cdot \mathbf{2}, \mathbf{1} \cdot \mathbf{2} \cdot \mathbf{3}$, and $\mathbf{1} \cdot \mathbf{3})$. This equilibrium occurred in solution until the formation of a HP low-soluble film $\mathbf{1} \cdot \mathbf{3}$ on the bottom part of the membrane. Then, the total concentration of 3 decreased, and the remaining nonprecipitating colloidal particles of $\mathbf{1 . 3}$ formed as a nucleation central core, which may further be surrounded by a HY shell of $\mathbf{1 \cdot 2}$ or $\mathbf{1 \cdot 2 \cdot 3}$ (Figure 4).

The resulted formation of microparticles prompted the selfassembly of the HY units of $\mathbf{1 \cdot 2}$ or $\mathbf{1 \cdot 2 \cdot 3}$ around the HP core of 1.3. An average microparticle diameter do indeed appear to be correlated with the concentration of $\mathbf{3}$; as expected, the growth of particles is more efficient when it is distributed over a smaller number of HP nucleation centers at the low concentration of 3, producing bigger particles and higher porosity in M4 (Figure $3 a-c)$, whereas the high concentration of the colloidal HP core of 1.3 resulted in the production of smaller HY.HP microparticles and lower porosity in $\mathbf{M} 7$ (Figure $4 \mathbf{j}-1$ ).

Finally, the membranes M4 and M7 were further applied to the water transport tests. The water permeabilities from top to bottom sides of membrane M4 were 1434 and $564 \mathrm{~L} \mathrm{~m}^{-2} \mathrm{~h}^{-1}$ $\mathrm{bar}^{-1}$, respectively, whereas those of membrane M7 were 1854 and $1332 \mathrm{~L} \mathrm{~m}^{-2} \mathrm{~h}^{-1} \mathrm{bar}^{-1}$, respectively. The higher permeability difference, almost triple, between the top and bottom of membrane M4 may mainly come from the asymmetric highly porous and dense morphological differences
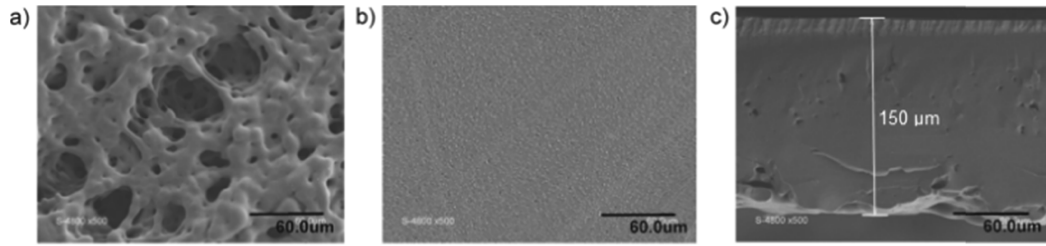

d)
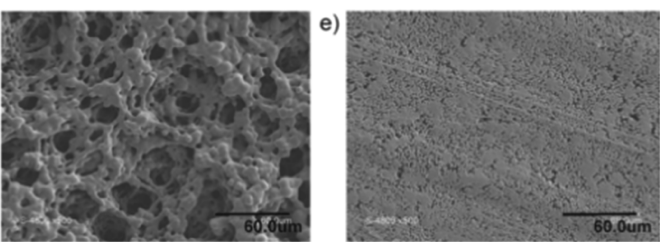

g)
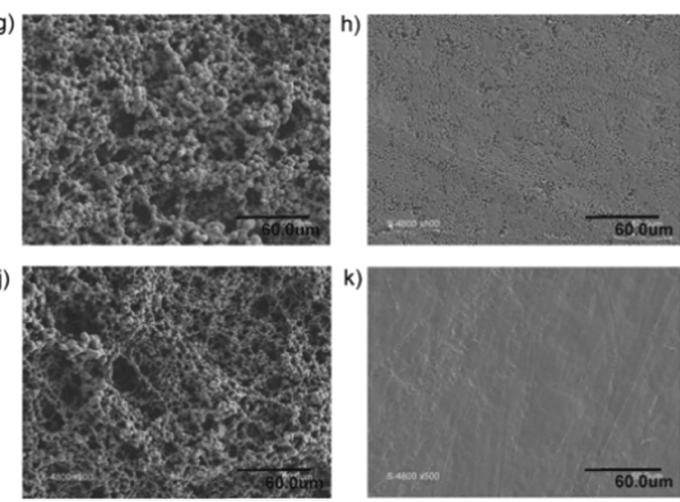
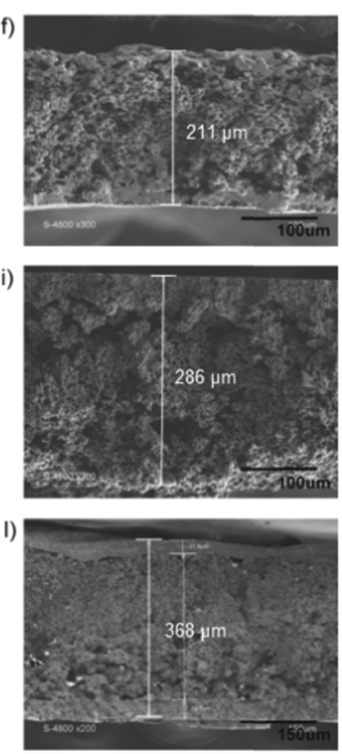

Figure 3. SEM micrographs of the top side (left), the bottom side (center) surfaces, and the cross section (right) of the membranes with different molar ratios of 2/3: (a-c) M4, 2:1; (d-f) M5, 3:2; (g-i) M6, 2:3; and (j-1) M7, 1:2. 


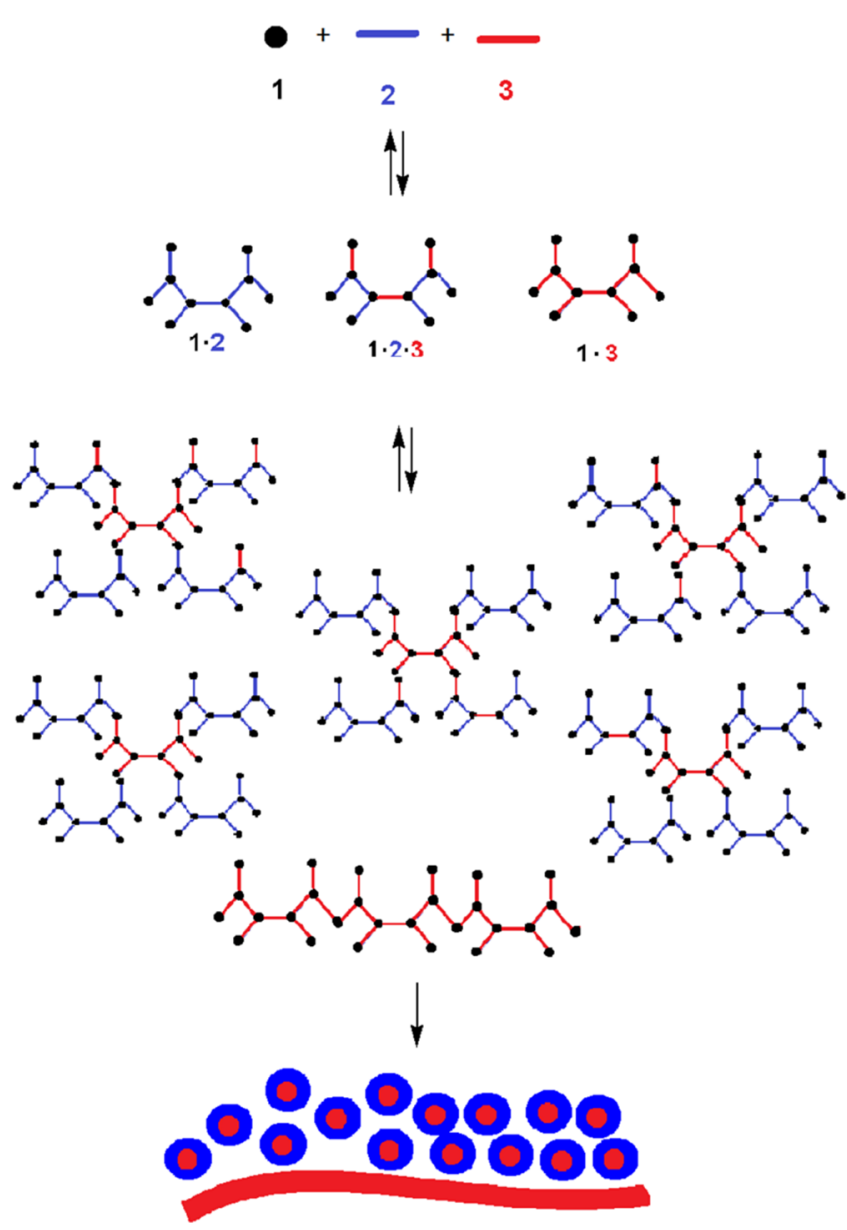

Figure 4. Proposed mechanism of segregation in a two-component system: the HP $\mathbf{1 \cdot 3}$ dynamers form a low-soluble thin film (red) on the bottom part of the membrane and of hybrid microparticles, prompting the self-assembly of the HY units of $\mathbf{1 \cdot 2}$ or $\mathbf{1 \cdot 2 \cdot 3}$ (blue corona) around HP (red core) $\mathbf{1 \cdot 3}$.

because their elemental distributions between the top and bottom were similar. By increasing the amount of HP 3, the top side of the membrane got less porous structures, whereas the bottom side was kept as a packed surface, leading to a lower difference for water permeability, despite the evident difference between the elemental distributions of the two HP and HY sides of the $\mathbf{M} 7$ membrane.

\section{CONCLUSIONS}

In conclusion, we have shown that a library of dynameric HP/ HY agonist building blocks can emerge via phase changes/ precipitation processes, resulting in the formation of asymmetric membranes composed of bottom HP thin layers and of top core-shell $\mathrm{HP} / \mathrm{HY}$ microparticles. Our results were supported by ${ }^{1} \mathrm{H}$ NMR, EDX, SEM, and DLS, and the uneven elemental distribution of the membranes was confirmed to come from the synergetic incorporation of $\mathrm{HY} / \mathrm{HP}$ components, driven by precipitation rates.

The hierarchical self-assembly process involves reversible covalent and noncovalent assemblies. This process is controlled at the molecular level, leading to a $\mathrm{HP} / \mathrm{HY}$ gradient from the bottom to the top of the membrane. Moreover, the membrane porosity can be controlled through the size of the core-shell $\mathrm{HP} / \mathrm{HY}$ microparticles, progressively decreasing with the increasing amount of the HP component. Systematic modifications on the ratios of the HY/HP components led to the membranes with controlled but different water permeabilities between the two sides of the membranes.

This work provided an insight into the simple and direct formation of asymmetric membranes with complex hierarchical structures via phase segregation of dynameric exchanging frameworks.

\section{ASSOCIATED CONTENT}

\section{S Supporting Information}

The Supporting Information is available free of charge on the ACS Publications website at DOI: 10.1021/acsomega.7b01645. Synthetic details, NMR, SEM, EDX, contact angle data, and water permeability test (PDF)

\section{AUTHOR INFORMATION}

\section{Corresponding Author}

*E-mail: mihail-dumitru.barboiu@umontpellier.fr (M.B.).

ORCID $\odot$

Mihail Barboiu: 0000-0003-0042-9483

\section{Present Address}

${ }^{\dagger}$ School of Pharmaceutical Sciences, Jiangnan University, Lihu Road 1800, 214122 Wuxi, P. R. China (Y.Z.).

\section{Notes}

The authors declare no competing financial interest.

\section{ACKNOWLEDGMENTS}

This work was supported by funds from ANR DYNAFUN and ANR-15-CE29-0009-02. We thank Ovidiu Ersen from IPCMS for the TEM analysis.

\section{REFERENCES}

(1) (a) Cragg, P. J. From Biological Inspiration to Biomedical Applications; Springer: Netherlands, 2010. (b) Huang, F.; Anslyn, E. V. Introduction: Supramolecular Chemistry. Chem. Rev. 2015, 115, 6999-7000. (c) Philp, D.; Stoddart, J. F. Self-Assembly in Natural and Unnatural Systems. Angew. Chem., Int. Ed. 1996, 35, 1154-1196. (d) Schneider, H.-J. Supramolecular Systems in Biomedical Fields: RSC: Cambridge, U.K., 2013.

(2) (a) Bos, J.; Browne, W. R.; Driessen, A. J. M.; Roelfes, G. Supramolecular Assembly of Artificial Metalloenzymes Based on the Dimeric Protein LmrR as Promiscuous Scaffold. J. Am. Chem. Soc. 2015, 137, 9796-9799. (b) Brosnan, S. M.; Schlaad, H.; Antonietti, M. Aqueous Self-Assembly of Purely Hydrophilic Block Copolymers into Giant Vesicles. Angew. Chem., Int. Ed. 2015, 54, 9715-9718.

(3) (a) Lehn, J.-M. From supramolecular chemistry towards constitutional dynamic chemistry and adaptive chemistry. Chem. Soc. Rev. 2007, 36, 151-160. (b) Miller, B. L. Dynamic Combinatorial Chemistry: in Drug Discovery. Bioorganic Chemistry and Materials Science; John Wiley and Sons: Hoboken, 2010. (c) Reek, J. N. H.; Otto, S. Dynamic Combinatorial Chemistry; Wiley-VCH: Weinheim, 2010. (d) Barboiu, M. Constitutional Dynamic Chemistry; Springer Verlag: Berlin, 2012; Vol. 322.

(4) Zhang, Y.; Barboiu, M. Constitutional Dynamic MaterialsToward Natural Selection of Function. Chem. Rev. 2016, 116, 809834.

(5) Barboiu, M.; Stadler, A.-M.; Lehn, J.-M. Controlled Folding, Motional, and Constitutional Dynamic Processes of Polyheterocyclic Molecular Strands. Angew. Chem., Int. Ed. 2016, 55, 4130-4154.

(6) Zhang, Y.; Legrand, Y.-M.; Petit, E.; Supuran, C. T.; Barboiu, M. Dynamic encapsulation and activation of carbonic anhydrase in multivalent dynameric host matrices. Chem. Commun. 2016, 52, 40534055 . 
(7) Catana, R.; Barboiu, M.; Moleavin, I.; Clima, L.; Rotaru, A.; Ursu, E.-L.; Pinteala, M. Dynamic constitutional frameworks for DNA biomimetic recognition. Chem. Commun. 2015, 51, 2021-2024.

(8) Lehn, J.-M. Dynamers: dynamic molecular and supramolecular polymers. Prog. Polym. Sci. 2005, 30, 814-831.

(9) Roy, N.; Bruchmann, B.; Lehn, J.-M. DYNAMERS: dynamic polymers as self-healing materials. Chem. Soc. Rev. 2015, 44, 37863807.

(10) Fukuda, K.; Shimoda, M.; Sukegawa, M.; Nobori, T.; Lehn, J.-M. Doubly degradable dynamers: dynamic covalent polymers based on reversible imine connections and biodegradable polyester units. Green Chem. 2012, 14, 2907-2911.

(11) Zhang, Y.; Barboiu, M. Dynameric asymmetric membranes for directional water transport. Chem. Commun. 2015, 51, 15925-15927.

(12) Barboiu, M. Multistate Phase Change Selection in Constitutional Multivalent Systems. Constitutional Dynamic Chemistry; Topics in Current Chemistry; Springer-Verlag Berlin Heidelberg, 2012; Vol. 322, pp 33-54.

(13) Ji, Q.; Lirag, R. C.; Miljanić, O. Š. Kinetically controlled phenomena in dynamic combinatorial libraries. Chem. Soc. Rev. 2014, 43, 1873-1884.

(14) Chen, C.; Tan, J.; Hsieh, M.-C.; Pan, T.; Goodwin, J. T.; Mehta, A. K.; Grover, M. A.; Lynn, D. G. Design of multi-phase dynamic chemical networks. Nat. Chem. 2017, 9, 799-880. 